\title{
Development and Validation of a Dissolution Test for 6 mg Deflazacort Tablets
}

\author{
Norma R. Sperandeo *, Diego E. Kassuha \\ Departamento de Farmacia, Facultad de Ciencias Químicas, Universidad Nacional de Córdoba. Ciudad \\ Universitaria. 5000-Córdoba, Argentine. \\ * Corresponding author. E-mail: nrscor@fcq.unc.edu.ar (N. R. Sperandeo) \\ Sci Pharm. 2009; 77: 679-693 \\ doi:10.3797/scipharm.0904-05 \\ Published: $\quad$ July $16^{\text {th }} 2009$ \\ Accepted: July $16^{\text {th }} 2009$ \\ Received: $\quad$ April $6^{\text {th }} 2009$ \\ This article is available from: http://dx.doi.org/10.3797/scipharm.090405 \\ (c) Sperandeo and Kassuha; licensee Österreichische Apotheker-Verlagsgesellschaft m. b. H., Vienna, \\ Austria. \\ This is an Open Access article distributed under the terms of the Creative Commons Attribution License \\ (http://creativecommons.org/licenses/by/3.0/), which permits unrestricted use, distribution, and reproduction \\ in any medium, provided the original work is properly cited.
}

\begin{abstract}
The aim of this study was to develop and validate a dissolution test for the quality control of deflazacort (DEF) tablets, a drug mainly used for the prevention of organ transplantation rejection, labeled as containing $6 \mathrm{mg}$ of active pharmaceutical ingredient (API), using an RP-HPLC method. After testing sink conditions and stability at $37^{\circ} \mathrm{C}$, DEF was found to be unstable, and decomposed as a function of the dissolution media. However, in water the decomposition was not significant enough to interfere with the determination of dissolution for DEF. The best conditions to carry out the dissolution test were paddle at $50 \mathrm{rpm}$, with $500 \mathrm{~mL}$ of deaerated water at $37^{\circ} \mathrm{C}$. Under these conditions, the in vitro release profiles of $6 \mathrm{mg}$ DEF tablets produced by two different laboratories, representing all approved products in the national market, shown to be dissimilar. A correlation between disintegration and in vitro dissolution was found for the two investigated formulations. The developed dissolution test was adequate for its purpose and can be applied for the quality control of $6 \mathrm{mg}$ DEF tablets.
\end{abstract}

\section{Keywords}

Quality control • In vitro release - RP-HPLC

\section{Introduction}

Drug absorption from a dosage form after oral administration depends on the release of the drug substance from the drug product, the dissolution and/or solubilization of the drug 
under physiologic conditions, and the permeability across the gastrointestinal tract [1]. Based on these considerations, the in vitro dissolution test for immediate release solid oral dosage forms has gained significance as being a very important tool in order to characterize drug product performance, to assess batch-to-batch quality of drug products, as well as to guide the development of new drug formulations [1].

Deflazacort $\quad(11 \beta, 16 \beta)-21$-(acetyloxy)-11-hydroxy-2'-methyl-5'H-pregna-1,4-dieno[17,16d]oxazole-3,20-dione, DEF) is a methyloxazoline derivative of prednisolone, that is used in rheumatoid arthritis, nephritic syndrome, organ transplantation rejection and juvenile chronic arthritis, among other diseases [2,3]. It is a poorly water-soluble compound [4] with an oral bioavailability of about $70 \%$, which exhibits low mineralocorticoid activity [5] and was promoted as a relatively bone-sparing glucocorticoid when compared with other glucocorticoids [2, 6, 7]. Although DEF was patented in 1966 [8] and is commercialized as tablets containing 6-mg or 30-mg per dose unit, it is still not coded [9] in the European Pharmacopoeia, the United States Pharmacopoeia (USP) or the Argentinian Pharmacopoeia (FNA). Consequently, as far as we know, there is no monograph of this active pharmaceutical ingredient (API) and no official method for the assessment of the dissolution characteristics of DEF tablets.

A review of the literature found a reversed phase-liquid chromatography (RP-HPLC) method reported for the determination of DEF in raw materials, drug products, biological fluids and in vitro drug dissolution studies [10]. After optimization and validation, the method was applied for the determination of both the API content as the dissolution rate of DEF from tablets containing $30 \mathrm{mg}$ of this API, using hydrochloric acid (HCL) $0.1 \mathrm{M}$ as the dissolution medium. However, only three tablets were tested, with selection of conditions and validation assays for the dissolution methodology not being reported. In 2006, a novel application of Near Infrared Spectroscopy (NIRS) for the determination of dissolution profiles of DEF in intact tablets was reported [11,12], and the results of the method were compared with the ones obtained by applying a dissolution method that used $900 \mathrm{~mL}$ of purified water containing $0.034 \mathrm{M} \mathrm{NaCl}$ and $0.087 \mathrm{M} \mathrm{HCl}$ at $\mathrm{pH} 1.1$, and UV spectrophotometry as the quantification method. In addition, Cardoso et al. [13] have recently reported a dissolution test for tablets and capsules containing $30 \mathrm{mg}$ of DEF, which uses $900 \mathrm{~mL}$ of $0.1 \mathrm{M} \mathrm{HCL}$ and UV spectrophotometry as detection method.

A common feature of all these methods is the evaluation of the dissolution characteristics of DEF tablets using an acidic medium of $\mathrm{pH} 1.0-1.1$. This is surprising since DEF is an ester prodrug that can be hydrolyzed in acidic media, as it occurs with aspirin whose hydrolysis to salicylic acid took place before the end of the dissolution test [14].

This present study describes the development and validation of a simple dissolution test for 6-mg DEF tablets, which was optimized on the basis of solubility and stability considerations. But, the most important objective was to compare the technical quality and dissolution characteristics of 6-mg DEF tablets commercialized in our country, since in Argentine renal and corneal transplanted patients use 6-mg DEF tablets daily for avoiding organ rejection, and differences in formulation could influence the release characteristics of the dosage forms questioning the interchangeability of the products. 


\section{Results and discussion}

\section{Solubility determination and dissolution test optimization}

Drug solubility and stability are important properties to be considered when selecting a dissolution medium [15]. In addition, it is generally considered advisable to use dissolution media with sink conditions, i.e. when the amount of substance dissolved in the dissolution medium at the end of the dissolution test did not exceed $30 \%$ of the saturation concentration) [16]. In order to test such conditions a preliminary study on DEF stability in Milli- $Q^{\circledR}$ water, simulated gastric fluid without pepsin (SGF) and simulated intestinal fluid without pancreatin (SIF) [17], was carried out using TLC (silica gel, dichloromethane-ethyl acetate 9:1). No DEF degradation products were detected in water during $6 \mathrm{~h}$ of testing. After that, a main degradation product, attributable to 21-desacetyldeflazacort, was noted by TLC analyses of the supernatant, indicating that DEF was partially degraded. On the other hand, In SGF and SIF, DEF degradation products were detected after $20 \mathrm{~min}$, indicating a poor stability of this API in both media. The low solubility in SIF was notable, with no DEF being detected in the supernatant even after $24 \mathrm{~h}$. Thus, these two media appear not suitable for a simple dissolution method, and In the case of studying the dissolution rate of DEF in HCL $0.087 \mathrm{M}$ or $0.1 \mathrm{M}[10,11,13]$, the decomposition of DEF should not to be ignored. Interestingly, McCormick et al. [14] developing a dissolution method for tablets containing aspirin and warfarin found that aspirin was unstable in phosphate buffer (the optimum medium for warfarin), and in order to quantitate the amount of aspirin that was originally present in tablets, the amount of salicylic acid formed by hydrolisis was converted to its aspirin equivalent and added to the amount of aspirin remaining in the sample to obtain the total amount of aspirin. A similar procedure should be followed for DEF in aqueous HCL; however, neither the decomposition pathways of DEF in aqueous media nor its degradation products are known at present. This will constitute our next task.

Hence, taking into account that from a routine quality control point of view the dissolution method should be as simple as possible, water appear to be an appropriate dissolution medium. Thus, the aqueous solubility of DEF at $37^{\circ} \mathrm{C}$ was determined by using a validated HPLC method (as it will be discussed in the following section) and the concentration free of degradation products was taken as a measure of its saturation concentration [18-20]. The value at $6 \mathrm{~h}$ was found to be $108 \mu \mathrm{g} / \mathrm{mL}$. Moreover, DEF continued to dissolve even after $16 \mathrm{~h}$ and at this time, its solubility was slightly higher. However, the experiment was then stopped since the presence of degradation products prevented the solubility equilibrium being reached [18]. Hence, although water is not an ideal medium [21], it was chosen as the dissolution medium on the basis of no degradation products were detected at least at $6 \mathrm{~h}$, which was sufficient time for dissolution profiles determination.

Considering the dose unit $(6 \mathrm{mg}$ ) and the total volume of the dissolution apparatus (900 $\mathrm{mL})$, DEF complete dissolution in water would correspond to $\sim 6.2 \%(6.67 \mu \mathrm{g} / \mathrm{mL})$ of the DEF solubility. So, even with water at $500 \mathrm{~mL}$, sink conditions prevailed. Thus, in order to improve sensitivity, a volume of $500 \mathrm{~mL}$ was chosen. The dissolution rate of DEF from tablets of product $A$ (taken as the reference product) was assessed at 50 and $75 \mathrm{rpm}$, the recommended speeds for apparatus 2 (Table 1). At $50 \mathrm{rpm}$, product A exhibited a very rapid dissolution, i.e. it released $>85 \%$ of DEF in $10 \mathrm{~min}$. Under these conditions, "conning" was not observed and the $\mathrm{pH}$ of the medium remained the same during the analysis. At 75 rpm, product $A$ improved its dissolution, as expected; however, the dissolution resulted too 
rapid, releasing $99.6 \%$ of DEF at $7.5 \mathrm{~min}$. The statistical $t$-Student test at 0.05 confidence level (paired media) was applied to compare the cumulative percentage of DEF released $(\% \mathrm{R})$, using 50 and $75 \mathrm{rpm}$. The $P$-value presented was slightly greater than the significance level (0.05), indicating that there was not statistically significant difference between the $\% \mathrm{R}$ at both stirring speeds. But, considering that a very rapid dissolution can mask differences among individual tablets and that at $50 \mathrm{rpm}$ "conning" was not observed, a speed of $50 \mathrm{rpm}$ was chosen.

Tab. 1. Effect of the paddle rotation speed on the cumulative percentage of DEF released $(\% \mathrm{R})$ from tablets of product $A$ in $500 \mathrm{~mL}$ of deaerated water at $37^{\circ} \mathrm{C}$.

\begin{tabular}{|c|c|c|c|c|}
\hline \multirow{2}{*}{$\begin{array}{l}\text { Time, } \\
\text { min }\end{array}$} & \multicolumn{2}{|l|}{$\% R\left( \pm S D^{a}\right)$} & \multirow[t]{2}{*}{$t$ test } & \multirow[t]{2}{*}{$P$} \\
\hline & 50 rpm & $75 \mathrm{rpm}$ & & \\
\hline 0.0 & 0.0 & 0.0 & & \\
\hline 5.0 & $51.6(3.5)$ & 78 (13) & & \\
\hline 7.5 & 74.7 (9.9) & 100 (15) & & \\
\hline 10.0 & $86.1(3.1)$ & $100.0(6.1)$ & -2.534 & 0.052 \\
\hline 15.0 & 96.4 (7.2) & $100.1(3.0)$ & & \\
\hline 20.0 & 99.7 (9.9) & $101.3(1.6)$ & & \\
\hline 30.0 & $100.2(5.2)$ & $101.6(2.4)$ & & \\
\hline
\end{tabular}

The effect of the dissolved gases in the medium on DEF dissolution was investigated at 50 rpm. As shown in Figure 1, non-deareation of the medium caused an important decrease in the amount of DEF dissolved from tablets of product $A$, and an increase in the variability of the results. Therefore, a deareated medium is necessary for evaluating the dissolution behavior of DEF.

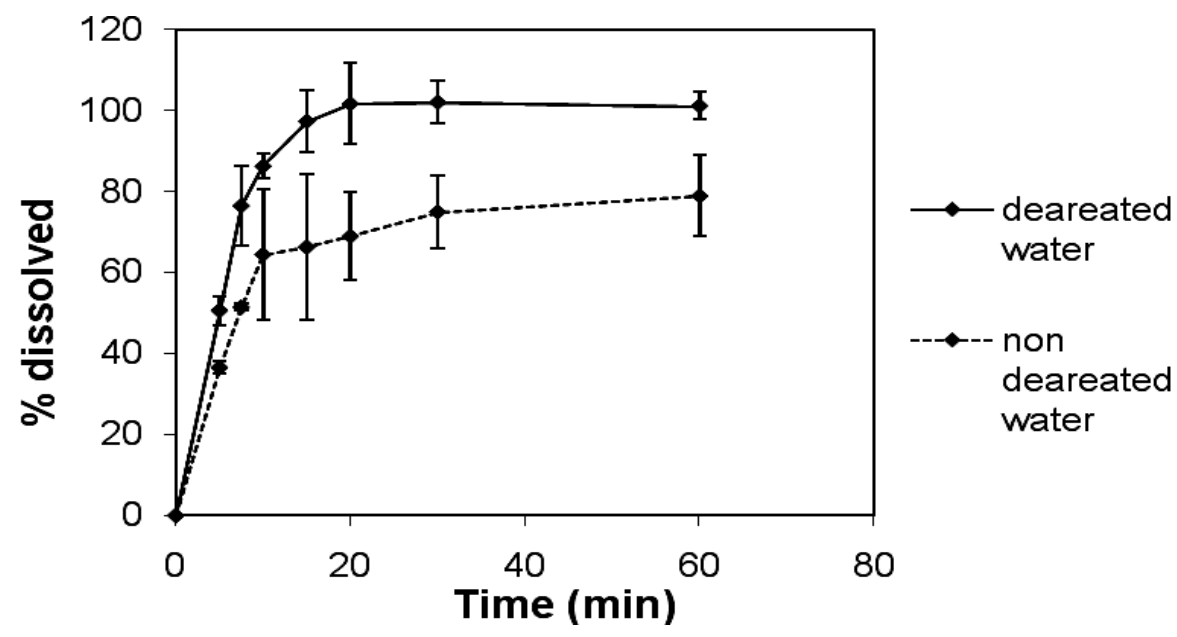

Fig. 1. Comparison of the DEF tablet's dissolution profiles (Product $A$ ) using deareated and non-deareated water $(500 \mathrm{~mL})$. Bars indicate the standard deviation. 
In consequence, $500 \mathrm{~mL}$ of deareated water appears an adequate medium for a routine quality control method, i.e. the decomposition of DEF is not significant enough to interfere with the dissolution determination, the $\mathrm{pH}$ of the medium remained unchanged after the end of the test, and also sink conditions prevailed.

\section{Dissolution test and HPLC validation}

Taking into account the instability of DEF, the analytical method was optimized in order to separate DEF from its degradation products. After several trials, it was noted that internal standards with retention times lower than that of DEF interfered with its degradation products, while, standards with higher retention times increased excessively the run times. Thus, the external standard method and a mixture of methanol and water $(80: 20 \mathrm{v} / \mathrm{v})$ were chosen for testing. In order to verify that the equipment was adequate for the analysis to be performed, system suitability tests were carried out. They were defined based on the results obtained in replicate injections of a standard solution of DEF $(20.0 \mu \mathrm{g} / \mathrm{mL})$. The obtained R.S.D. value for the peak area of the analyte was $0.26 \%$, indicating an acceptable system precision. The capacity factor $\left(k^{\prime}\right)$ was $>2(2.47)$, the number of theoretical plates $(N)$ was $>2000(4200)$ and the tailing factor, measured at $5 \%$ of the peak height, was <2.00 (1.46). The results of system suitability testing, in comparison with specifications [17,22], indicated that the proposed chromatographic conditions achieved reasonable retention and symmetric peak shapes for DEF. In fact, DEF degradation peaks were observed after acid, alkaline, light and thermal treatments, and resolved from the DEF one (Supporting information). Table 2 shows the percentages of DEF recovered after such treatments. In addition, no interference from excipients was observed in the tablet dosage forms (Supporting information). The dissolution test specificity also confirmed these results, as no interference from the excipients was found, i.e. the statistical $t$-test at the 0.05 significance level indicated no significant difference $(P=0.49)$ between the \%R from tablets and the content of a $12 \mu \mathrm{g} / \mathrm{mL}$ DEF standard solution.

Tab. 2. Degradation of DEF in selected conditions.

\begin{tabular}{|c|c|c|c|}
\hline Condition & $\begin{array}{l}\text { Time, } \\
\text { h }\end{array}$ & $\begin{array}{l}\text { Recovery, } \\
\%\end{array}$ & $\begin{array}{l}\mathrm{RRT}^{\mathrm{a}} \text { of } \\
\text { Degradation products }\end{array}$ \\
\hline DEF standard solution + $\mathrm{HCl} 0.1 \mathrm{M}\left(\mathrm{RT}^{\mathrm{b}}\right)$ & 0.5 & 97.7 & $3.45 ; 5.40$ \\
\hline $\mathrm{DEF}$ standard solution $+\mathrm{HCl} 0.1 \mathrm{M}\left(\mathrm{RT}^{\mathrm{b}}\right)$ & 5 & 83.2 & $3.45 ; 5.40$ \\
\hline DEF standard solution $+\mathrm{NaOH} 0.1 \mathrm{M}(\mathrm{RT})$ & 5 & 85.8 & $3.52 ; 5.30$ \\
\hline DEF standard solution, dark (RT) & 5 & 100.0 & None detected \\
\hline DEF standard solution, daylight (RT) & 5 & 98.5 & $3.95 ; 5.38$ \\
\hline DEF standard solution, dark $\left(4^{\circ} \mathrm{C}\right)$ & 48 & 95.9 & $3.52 ; 5.30$ \\
\hline DEF standard solution, $80^{\circ} \mathrm{C}$ & 5 & 76.8 & $2.60 ; 4.68 ; 5.43$ \\
\hline
\end{tabular}

${ }^{a}$ RRT: relative retention time. ${ }^{b} \mathrm{RT}$ : room temperature.

To assess the linearity, three standard curves for DEF were constructed, plotting micrograms injected versus peak areas on the $1-20 \mu \mathrm{g} / \mathrm{mL}$ concentration range. As the nominal concentration of DEF in $500 \mathrm{~mL}$ should be $12 \mu \mathrm{g} / \mathrm{mL}$, the above range brackets this level. The regression equation was: $y=(2678 \pm 21) 10^{3} . x+(6.6 \pm 4.5) 10^{3}$, where $x$ is $\mu \mathrm{g}$ injected and $\mathrm{y}$ is peak area. The relative standard deviation (RSD of the slope was $0.78 \%$, the coefficient of determination $\left(R^{2}\right)$ was 0.9991 and the $y$-intercept was not 
significantly different from zero at the $95 \%$ confidence level. The data was confirmed by means of analysis of variance (ANOVA), which demonstrated a significant linear regression and non-significant linearity deviation $(P<0.05)$.

The assessment of the method precision (Table 3) indicated that it was acceptable, i.e. the RSD values were all below $1 \%$, with the intermediate precision also being found to be adequate (RSD values $<1 \%$ ). On the other hand, in the accuracy tests, the method was found to be accurate based on its intended use. As indicated in Table 4, the mean recoveries for both products ranged from $99.65 \%$ to $100.52 \%$ with $\mathrm{RSD}$ values $<1 \%$.

Tab. 3. Precision of the assay method: repeatability and intermediate precision.

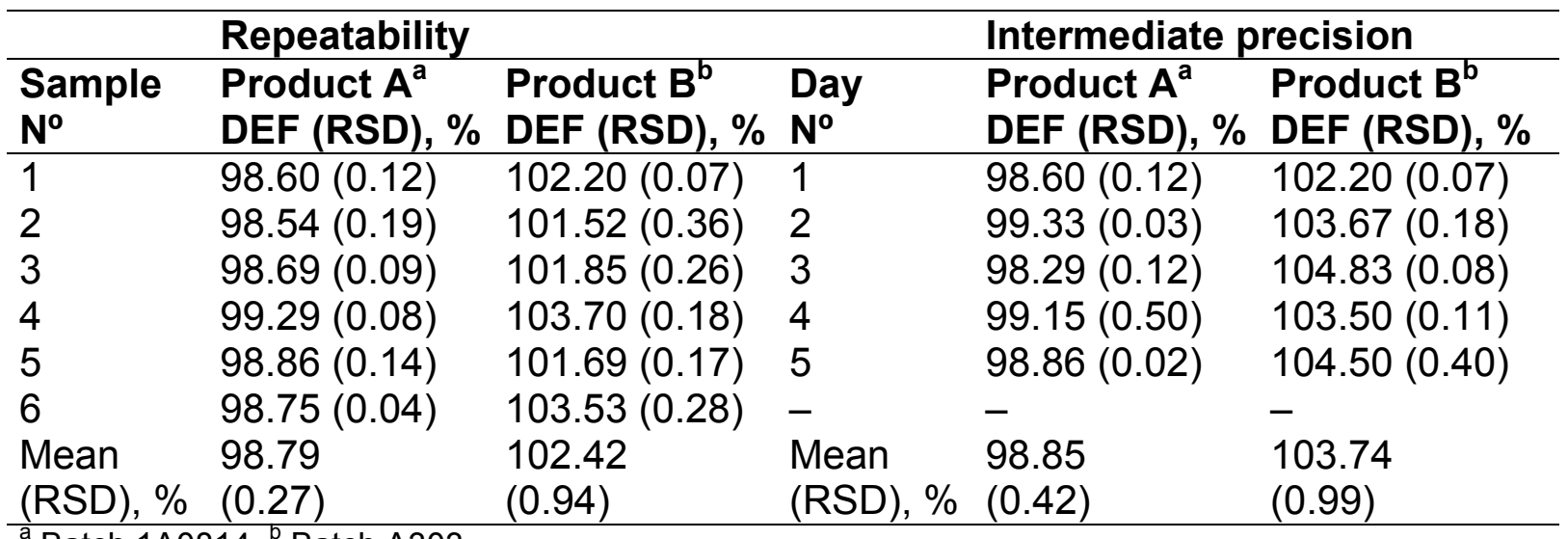

${ }^{a}$ Batch 1A0814. ${ }^{\mathrm{b}}$ Batch A303.

Tab. 4. Recovery analysis for DEF tablets, using the HPLC method.

\begin{tabular}{llll}
\hline Product & \multicolumn{3}{l}{ Concentration level, \% w/w } \\
\cline { 2 - 4 } & $\mathbf{8 0}$ & $\mathbf{1 0 0}$ & $\mathbf{1 2 0}$ \\
\hline $\mathrm{A}$ & 99.94 & 100.58 & 100.21 \\
& 99.80 & 100.48 & 100.10 \\
Mean (RSD), \% & 99.50 & 100.50 & 100.31 \\
$B$ & $99.75(0.23)$ & $100.52(0.05)$ & $100.16(0.36)$ \\
& 100.34 & 99.47 & 100.40 \\
& 99.99 & 99.69 & 100.78 \\
Mean (RSD), \% & 99.99 & 99.80 & 101.15 \\
${ }^{a}$ Batch 1A0814. ${ }^{\circ}$ Batch A303. & $100.11(0.20)$ & $99.65(0.17)$ & $100.18(0.54)$ \\
\hline
\end{tabular}

The accuracy of the dissolution test was also verified by recovery experiments (Table 5).

Percentage recoveries of $100 \pm 5 \%$ have been previously recommended for the accuracy test [15]. As mean recoveries ranged from $100.1 \%$ to $103.5 \%$, this showed that the dissolution method was accurate. 
The ruggedness of the dissolution test was evaluated, and the results are shown in Figure 2. The effect of rotation speed was noticeable only at $5 \mathrm{~min}$, where the disintegration and dissolution were favored by the increased stirring speed. Above $5 \mathrm{~min}$, the variation in the $\% R$ was less than $\pm 5 \%$ [23] of that the optimal experimental conditions. The variation in the $\% R$ with the temperature change was also less than $\pm 5 \%$ at all time points, confirming the ruggedness of the test.
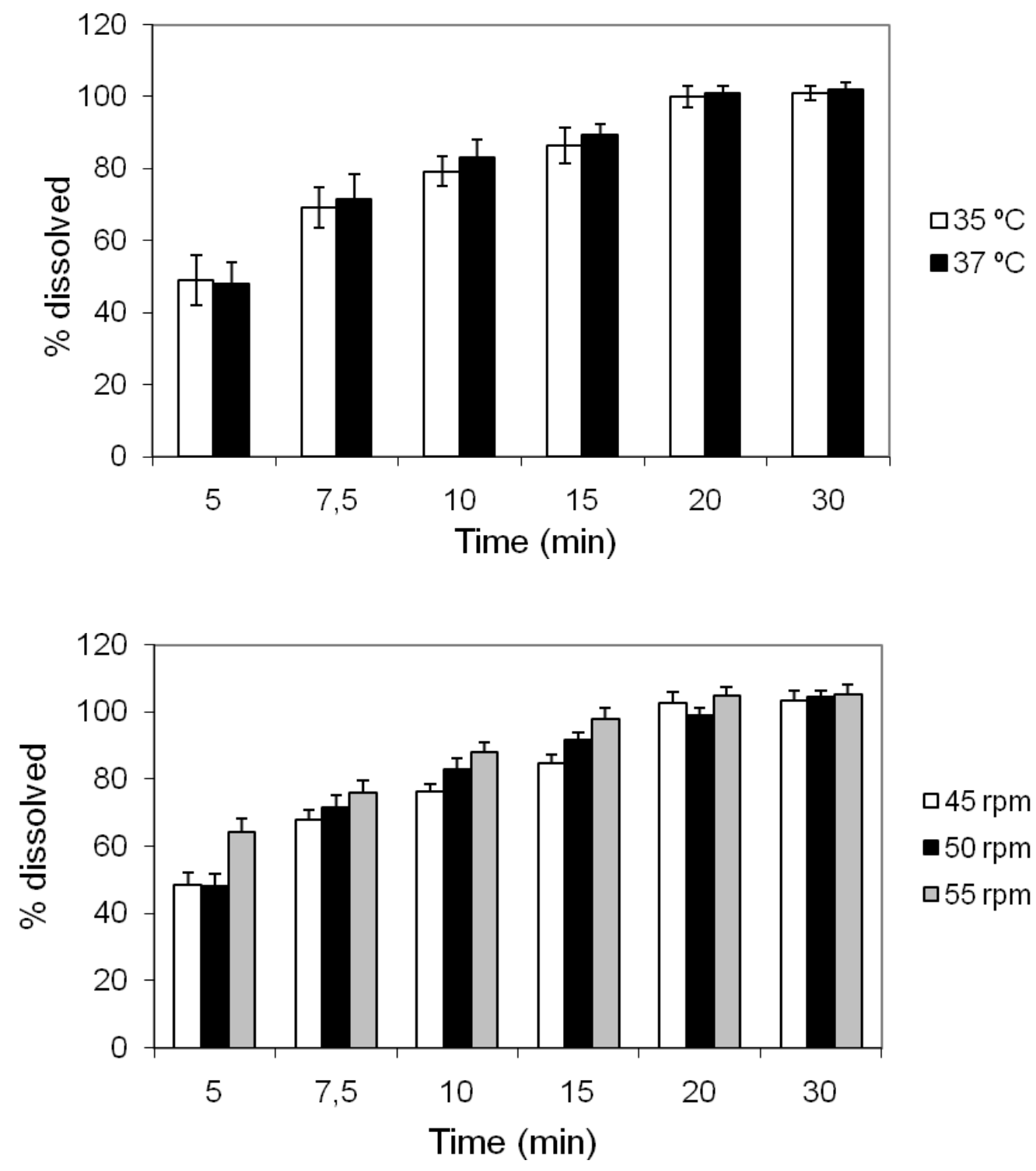

Fig. 2. Ruggedness of the dissolution test against paddle rotation speed and temperature variation (Product $A$ ). 
Tab. 5. Accuracy data for the dissolution method.

\begin{tabular}{lcl}
\hline $\begin{array}{l}\text { Concentration } \\
\text { level, \% w/w }\end{array}$ & $\begin{array}{c}\text { Recovery } \\
(\%)\end{array}$ & $\begin{array}{l}\text { Average } \\
\text { recovered (RSD), \% }\end{array}$ \\
\hline 80 & 103.50 & \\
80 & 103.19 & $103.5(0.24)$ \\
80 & 103.67 & \\
\hline 100 & 99.37 & \\
100 & 99.72 & $100.1(1.0)$ \\
100 & 101.29 & \\
\hline 120 & 104.96 & \\
120 & 98.72 & $101.4(3.2)$ \\
120 & 100.49 & \\
\hline \multicolumn{2}{l}{ Mean (RSD), \% $101.6(2.2)$} \\
\hline${ }^{a}$ Product A (Batch1A0814).
\end{tabular}

The dissolution profiles of products $A$ and $B$ in the optimized conditions are shown in Figure 3. A visual inspection of the resulting profiles clearly indicates that both products are inequivalent in their dissolution behavior. In accordance, One-way ANOVA [24, 25] indicated that the \% R for products $A$ and $B$ were statistically different at each time point ( $P$ $=0.00)$. These results were confirmed by the Welch and Brown-Forsythe tests, which also gave $P$ values $=0.00$ at each time point, indicating that product $A$ was significantly different from product $B$ in its dissolution behaviour.

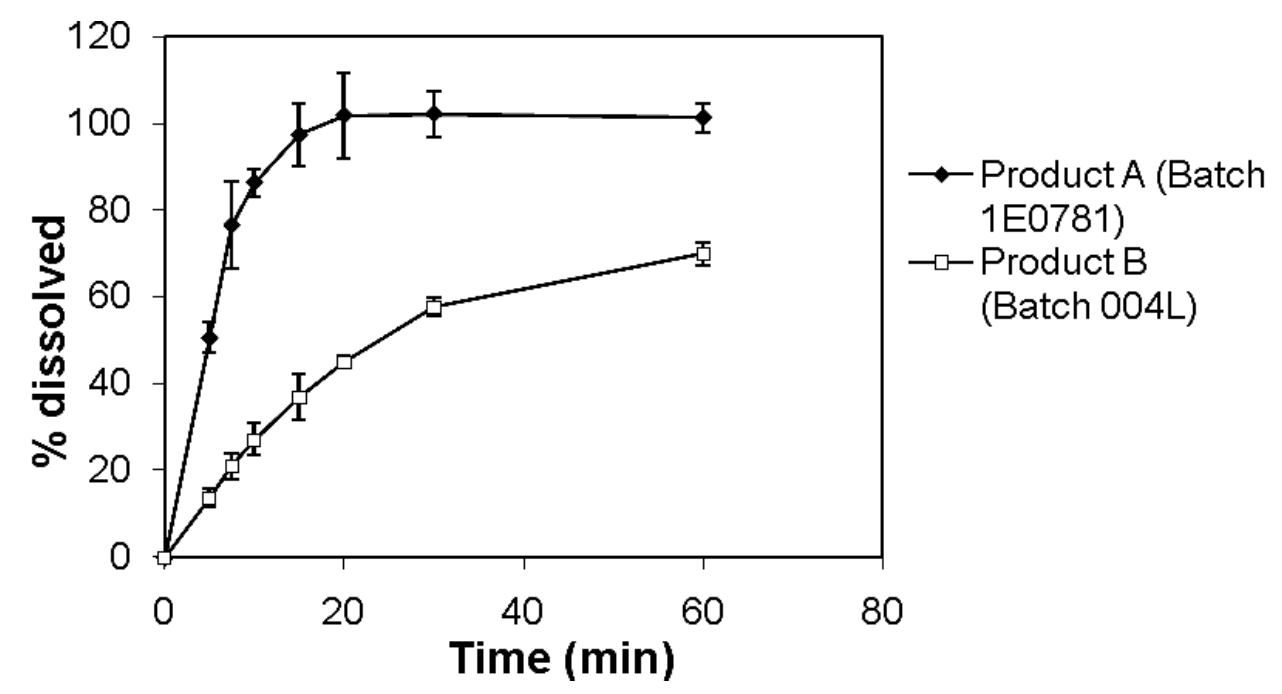

Fig. 3. Mean dissolution profiles ( $n=6)$ of DEF from products $A$ and $B$ in $500 \mathrm{~mL}$ of deaerated water at $37^{\circ} \mathrm{C}$ and $50 \mathrm{rpm}$ (Bars indicate the standard deviation).

The validated dissolution method was also applied to the quality control of three batches of product $A$, as shown in Figure 4. According to ANOVA test, the profiles were not significantly different in terms of the $\% R$ at each time point $(P>0.05)$, indicating good manufacturing reproducibility for product $A$. 


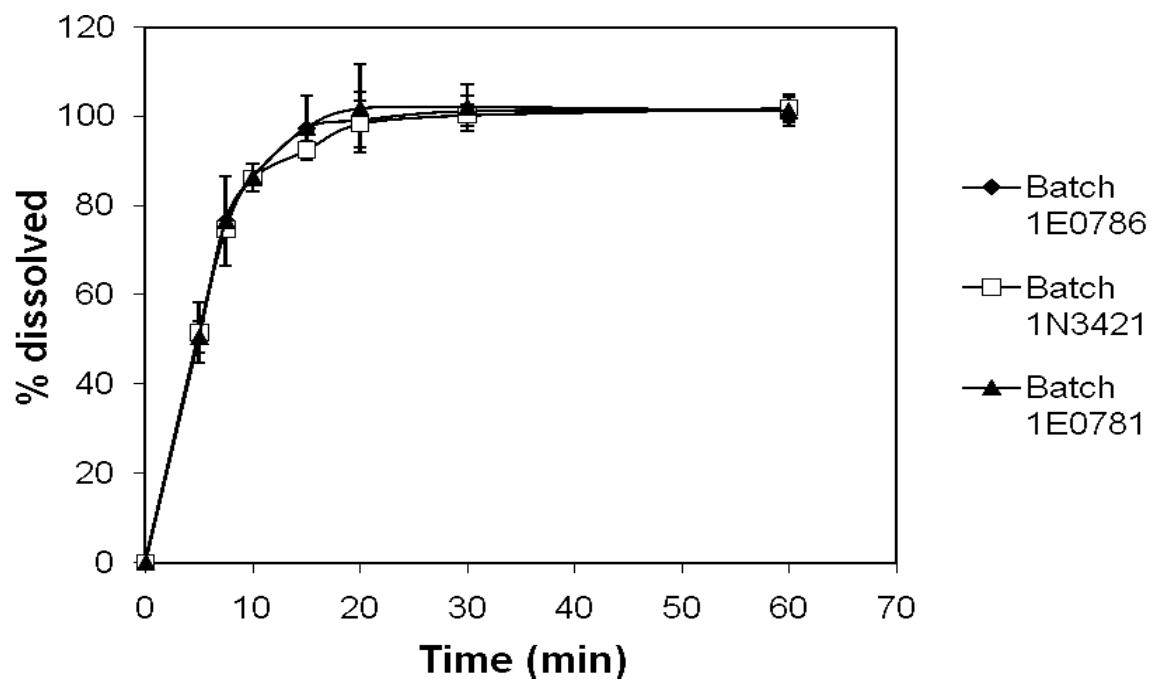

Fig. 4. Mean dissolution profiles $(n=6)$ of three batches of product $A$ in deaerated water at $37^{\circ} \mathrm{C}$ and $50 \mathrm{rpm}$ (Bars indicate the standard deviation).

\section{Pharmacotechnic tests}

In order to evaluate the technical quality of DEF tablets, various physical tests were conducted and the results presented in Table 6 . It was determined that both products fitted with the specified limitation for tablet weight variation (the mean weight $\pm 15 \%$ ) and with the recommended hardness range $(2-8 \mathrm{Kg})$. Moreover, the average tablet weight and hardness did not differ significantly between products (Table 6 ).

Tab. 6. Physical characteristics of the investigated formulations.

\begin{tabular}{|c|c|c|}
\hline Characteristic & Product $\mathrm{A}^{\mathrm{a}}$ & 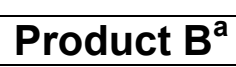 \\
\hline Tablet weight (mg) & $186.2(1.1)$ & $193.0(1.4)$ \\
\hline Hardness $(\mathrm{Kg})$ & $5.58(27)$ & $5.02(28)$ \\
\hline Thickness (mm) & $2.47(0.89)$ & $2.61(2.0)$ \\
\hline Diameter (mm) & $12.74(0.60)$ & $13.23(0.37)$ \\
\hline Disintegration time ${ }^{b}$ & 2'50" & 5'19"' \\
\hline Drug content (mg) & $6.2(1.2)$ & $6.2(2.0)$ \\
\hline Batch & 1E0781 & 004L \\
\hline
\end{tabular}

The average drug content of both products was identical, within the experimental error, and complied with the pharmacopoeial criteria for related corticoids $(100 \pm 10 \%$ of the labeled amount) [17]. In contrast, a marked difference was found in the tablet disintegration times, being evident a relation between disintegration time and in vitro dissolution. Product $A$ showed the shortest disintegration time, which seemed to be reflected in its fast release in vitro (Figures 4 and 5). Meanwhile, product $B$ exhibited a 
lower dissolution, with its disintegration time being almost double. Thus, the dissolution differences were reflected in the disintegration behavior of the products.

In summary, a simple dissolution test for evaluating the in vitro biopharmaceutical quality of 6-mg DEF tablets was developed and validated. The method was found suitable to study the dissolution of this API, finding significantly different release profiles for the two products commercialized in our country, which indicates that the developed dissolution method has enough discriminatory power to reflect formulation differences. Taking into account that product $A$ is a very rapidly dissolving product; it appears that there exist fewer ramifications for the DEF bioavailability in product $A$ than in product $B$, which was found to be a very slowly dissolving product, so its interchangeability may be seriously considered. Nevertheless, in vivo bioavailability studies should be conducted in order to confirm any correlation with the in vitro performance of DEF products.

\section{Experimental}

\section{Materials}

DEF (99.2\% purity) was further purified by recrystallization from ethyl acetate in order to obtain a working standard whose purity was then checked by several techniques, including DSC and TG (MDSC 2920 and TG 2950 analyzers, TA Instruments, New Castell, DE, USA), Hot stage microscopy (Leitz, Wetzlar, Germany) and Power X-ray diffractometry (D8 Advance, Bruker, Germany) studies. Milli-Q ${ }^{\circledR}$ water (Millipore, Bedford, USA) was used for both the dissolution media and the HPLC mobile phase. All other reagents and chemicals were of analytical or HPLC grade (Sintorgan S.A.). Nylon membranes (0.45- $\mu \mathrm{m}$ pore size, Pall Corporation) and Teflon filters (10- $\mu \mathrm{m}$, Hanson Research, P/N 27-101-074) were commercially acquired. DEF tablets were obtained locally from pharmacies in Cordoba city. The investigated products were:

Product A: Azacortid ${ }^{\circledR} 6$ (Aventis, Italy), labeled as containing $6 \mathrm{mg}$ of DEF and the following excipients: lactose, microcrystalline cellulose, magnesium stearate and cornstarch.

Product B: Flamirex ${ }^{\circledR} 6 \mathrm{mg}$ (Sanofi-Synthelabo, Argentine) labeled as containing $6 \mathrm{mg}$ of DEF and the following excipients: corn starch, calcium phosphate dibasic, microcrystalline cellulose, polyvinyl pyrrolidone, crosscarmellose and magnesium stearate.

\section{Methods}

\section{II.a Dissolution studies}

Dissolution was conducted using a Hanson SR6 dissolution tester (Hanson Research, CA, USA) using USP Apparatus 2 at a temperature of $37.0 \pm 0.5^{\circ} \mathrm{C}$. For all experiments, filtered (Teflon filters fitted to the stainless steel cannulas of the dissolutor) aliquots $(5 \mathrm{~mL})$ were withdrawn with replacement at appropriate time intervals, using a $5 \mathrm{~mL}$ syringe. All the sample solutions were protected from the light until being analyzed. Due to the limited number of samples, 3-6 tablets per formulation were tested in the development and validation stage, and six in the optimized conditions. The cumulative percentage of API released (\%R) was determined by HPLC assay. Checks for adsorption to the filters were performed by preparing DEF solutions at the nominal concentration in dissolution media, 
and then passing them through the filters. This procedure was repeated during 15 min. The results of these studies revealed no significant loss of API.

\section{II.b Solubility experiments}

An excess amount of DEF working standard (10 $\mathrm{mg}$, mildly ground in an agate mortar) was introduced into screw-capped vials containing $7 \mathrm{~mL}$ of the appropriate solvent [Milli$Q^{\circledR}$ water, simulated gastric fluid without pepsin (SGF) and simulated intestinal fluid (SIF) without pancreatin ( $\mathrm{pH}$ 6.8)] in a shaking water bath at $37^{\circ} \mathrm{C}$. At suitable time intervals, samples were collected, filtered $(0.45-\mu \mathrm{m})$, and analyzed by TLC (silica gel, dichloromethane-ethyl acetate 9:1, UV detection) to detect DEF degradation products. Residual solid materials were also analyzed post-assay using TLC. After that, the solubility of DEF was determined in water as described, but assessing the amount dissolved by HPLC. All tests were performed in duplicate.

\section{II.c Chromatographic conditions}

The HPLC system consisted of a Spectra System P2000 pump, a Rheodyne ${ }^{\circ} 20 \mu \mathrm{L}$ fixed loop injector (7125 model), a variable UV-Visible detector (Thermo Separation Products) and a Chromatopac integrator (Spectra System). Chromatography was performed on a

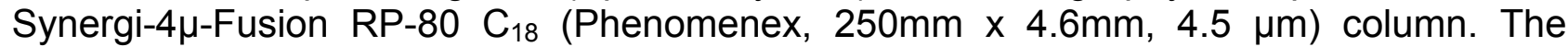
mobile phase was a mixture of methanol and water $(80: 20, \mathrm{v} / \mathrm{v})$, which was filtered $(0.45-$ $\mu \mathrm{m})$ and degassed using vacuum before use. All analyses were performed at room temperature $\left(\mathrm{RT}, 20-25^{\circ} \mathrm{C}\right.$ ) at a flow rate of $0.8 \mathrm{~mL} / \mathrm{min}$. Detection was made at $245 \mathrm{~nm}$ (0.01 a.u.f.s). Under these conditions, DEF retention time was roughly $6.5 \mathrm{~min}$. Triplicate $20 \mu \mathrm{L}$ injections were made for each analysis. Peak areas were integrated using the program Peak Simple ${ }^{1} 1.0$ for Windows.

\section{II.d Dissolution test and HPLC validation}

The dissolution test and the HPLC method were validated through the determination of stability, specificity, linearity, accuracy/precision and ruggedness [15, 17, 27, 28].

Prior to injecting solutions, the column was equilibrated for at least 30 min with the mobile phase flowing through the system. System suitability tests were carried out by making six replicate injections of a standard solution containing $20.0 \mu \mathrm{g} / \mathrm{mL}$ of DEF, and analyzing the chromatograms for DEF peak area, theoretical plates $(N)$, capacity and tailing factors. Acceptable results for these parameters, calculated using reported equations $[17,22]$ were required before sample analysis.

Stability and specificity: To investigate the stability of DEF and the ability of the HPLC method to separate it from its degradation products, forced degradation studies were performed, using acid, base, heat $\left(80^{\circ} \mathrm{C}\right)$ and daylight. Degradation samples were obtained by transferring $1 \mathrm{~mL}$ of a $180 \mu \mathrm{g} / \mathrm{mL}$ DEF stock standard solution (in mobile phase) into screw-capped vials, and adding $9 \mathrm{~mL}$ of $\mathrm{HCL} 0.1 \mathrm{M}, \mathrm{NaOH} 0.1 \mathrm{M}$ or mobile phase (heat and light effect). Also, the stability of the stock solution was evaluated for $48 \mathrm{~h}$ at $4{ }^{\circ} \mathrm{C}$ in the dark. After suitable time intervals, the solutions were neutralized (where corresponding), filtered and assayed, verifying the chromatograms obtained (peak areas and degradation products formation). The dissolution test specificity was assessed by determining the \%DR from tablets $(n=3)$ in $500 \mathrm{~mL}$ of water at $37.0{ }^{\circ} \mathrm{C}$ with a stirring speed 
of $150 \mathrm{rpm}$. Sample aliquots were withdrawn, filtered, analyzed by HPLC and compared with a DEF standard solution of about $12 \mu \mathrm{g} / \mathrm{mL}$

Linearity: Aliquots of a $200 \mu \mathrm{g} / \mathrm{mL}$ DEF stock solution were transferred to $10-\mathrm{mL}$ volumetric flasks to obtain six standard solutions $(1-20 \mu \mathrm{g} / \mathrm{mL}$ range). The solutions were prepared on different days $(n=3)$ in order to test inter-day linearity and they were injected in triplicate every day. Linearity was evaluated by the least squares regression method and ANOVA.

Precision: For the method precision, the repeatability and intermediate precision were determined by assaying samples of product $A$ and $B$ at the same concentration, under the same experimental conditions, during the same day (preparing six sample solutions) and in five different days, respectively. Thus, ten tablets of each product were crushed to fine powder. An accurately weighed amount of powder equivalent to $8 \mathrm{mg}$ of DEF was placed in a 50-mL volumetric flask and methanol $(2 \mathrm{~mL})$ was added to favor the solubilization of the drug. Then, $10 \mathrm{~mL}$ mobile phase were added, the mixture sonicated for $15 \mathrm{~min}$, and the volume was completed with the same diluent. This mixture was then mixed and filtered. The first $10 \mathrm{~mL}$ were rejected, and $1 \mathrm{~mL}$ of the filtrate was transferred to a $10-\mathrm{mL}$ volumetric flask and diluted with mobile phase. The solution was filtered before the HPLC analysis. Precision was evaluated based on the RSD of the results.

Accuracy: it was assessed at 80,100 and $120 \%$ of the assay of DEF by recovery experiments, where the assay method was applied to portions of powdered tablets spiked with known amounts of DEF. The accuracy of the dissolution test was evaluated by recovery tests of known amounts of DEF (at 80,100 and $120 \%$ of the label claim) added to tablets. Accurately weighted portions of DEF were dissolved in methanol $(3 \mathrm{~mL})$ and quantitatively transferred to vessels containing water (preheated at $37^{\circ} \mathrm{C}$ ) to a final volume of $500 \mathrm{~mL}$. Then, tablets of product $A$ were dropped and rotated for $15 \mathrm{~min}$ at $150 \mathrm{rpm}$. Aliquots were withdrawn, and suitably diluted with mobile phase before being assayed by HPLC.

Ruggedness: It was evaluated through small, deliberate variations of some critical parameters such as paddle rotation speed and temperature. The stirring speed was varied in the range of $45.0-55.0 \mathrm{rpm}$, and two temperatures were assayed $\left(35.0\right.$ and $\left.37.0{ }^{\circ} \mathrm{C}\right)$.

\section{II.e Applied methods to compare dissolution profiles}

Where appropriate, Student $t$-test or Univariate ANOVA was used to compare the data $[24,25]$. In ANOVA, the percentages dissolved were tested separately at each time point to see if there were differences among the conditions or products. Post hoc procedures were also applied to determine when the differences arose. The data were considered to be significant when $P<0.05$.

\section{II.f Pharmaceutical quality control tests}

Tablets of each formulation were subjected to the following tests: a) Weight variation: Each tablet $(n=10)$ belonging to each formulation was weighted on an electronic balance (Mettler H-72). b) Hardness: This test was applied with a tablet hardness tester (AVIC DU4 07MR98, Argentine). Six tablets of each product were individually put into the tester and the 'resistance to crushing' was measured. c) Thickness: the thickness of tablets $(n=6)$ from each product was measured with the micrometer included on the tablet hardness 
tester. d) Assay: it was performed following the procedure described under precision. e) Disintegration: Tablets $(n=6)$ of each formulation were subjected to a disintegration test according to the FNA $7^{\circ}$ Edition $\left(37.0 \pm 0.5^{\circ} \mathrm{C}\right.$, water and basket rack assembly) [26] using a QC-21 Hanson disintegrator tester.

\section{Acknowledgements}

Financial support from SECyT-UNC, CONICET and FONCyT of Argentine is acknowledged.

\section{Supporting Information}

4 typical chromatograms for (a) DEF standard, (b) Product A, (c) Product B and (d) DEF standard after acid degradation (aqueous $\mathrm{HCL} 0.1 \mathrm{M}$ ) are available in the online version (Format: PDF, Seize: < 0.1 MB): http://dx.doi.org/10.3797/scipharm.0904-05.

\section{Authors' Statement}

\section{Competing interests}

The authors declare no conflict of interests

\section{References}

[1] FDA.

Guidance for industry, Dissolution tests for immediate release solid oral dosage forms.

U.S. Department of health and human services, Food and Drug Administration, Center for Drug Evaluation and Research (CEDER), FDA; 1997.

[2] Markham A, Bryson HM.

Deflazacort - A review of its pharmacological properties and therapeutic efficacy.

Drugs. 1995; 50: 317-333.

doi:10.2165/00003495-199550020-00008

[3] Di Munno O, Mazzantini N, Milani S, Pasero G.

Clinical equivalence between Deflazacort oral drops and tablets in active rheumatoid arthritis.

Clin Rheumatol. 1999; 18: 140-144. doi:10.1007/s100670050072

[4] Available at http://www.newellchem.com/deflazacort.htm (Accessed March 4, 2008)

[5] Grossmann C, Scholz T, Kochel M, Bumke-Vogt C, Oelkers W, Pfeiffer AFH, Diederich S, Bahr V. Transactivation via the human glucocorticoid and mineralocorticoid receptor by therapeutically used steroids in CV-1 cells: a comparison of their glucocorticoid and mineralocorticoid properties.

Eur J Endocrinol. 2004; 151: 397-408.

doi:10.1530/eje.0.1510397

[6] Cooper MS.

Sensitivity of bone to glucocorticoids.

Clin Sci. 2004; 107: 111-123; and references therein. doi:10.1042/CS20040070

[7] Mollmann H, Hochhaus G, Rohatagi S, Barth J, Derendorf H.

Pharmacokinetic/pharmacodynamic evaluation of deflazacort in comparison to methylprednisolone and prednisolone.

Pharm Res. 1995; 12: 1096-1100.

doi:10.1023/A:1016287104656 
[8] Budavari S, O'Neil MJ, Smith A, Heckelman PE (eds.).

The Merck Index.

11th Edition, Merck \& Co. Inc. Rahway, NJ, USA, 1989, p. 449.

[9] Martindale: The Complete Drug Reference. Electronic version. London. Pharmaceutical Press; 2005 [Accessed October 26, 2008].

[10] Ozkan Y, Savaser A, Tas C, Uslu B, Ozkan SA.

Drug dissolution studies and determination of deflazacort in pharmaceutical formulations and human serum samples by RP-HPLC.

J Liq Chromatogr Rel Technol. 2003; 26: 2141-2156.

doi:10.1081/JLC-120022399

[11] Blanco M, Alcala M, Gonzalez JM, Torras E.

A process analytical technology approach based on NIR Spectroscopy: tablet hardness, content uniformity, and dissolution test measurements of intact tablets.

J Pharm Sci. 2006; 95: 2137-2144.

doi:10.1002/jps.20653

[12] Blanco M, Alcala M, Gonzalez JM, Torras E.

Determination of dissolution profiles in intact pharmaceutical tablets by NIR spectroscopy.

J Process Anal Technol. 2006; 3: 25-28.

[13] Cardoso SG, Correa GM, Bellé LP.

Desemvolvimiento e Validacao de Método de Dissolucao para Deflazacorte em Comprimidos e

Cápsulas Magistrais.

Lat Am J Pharm. 2008; 27: 734-739.

[14] McCormick TJ, Gibson AB, Diana FJ.

Development and validation of a dissolution method for warfarin sodium and aspirin combination tablets.

J Pharm Biomed Anal. 1997; 15: 1881-1891.

doi:10.1016/S0731-7085(96)01891-2

[15] Rossi RC, Dias CL, Donato EM, Martins LA, Bergold AM, Froehlich PE.

Development and validation of a dissolution test for ritonavir soft gelatin capsules based on in vivo data.

Int J Pharm. 2007; 338: 119-124.

doi:10.1016/j.ijpharm.2007.01.036

[16] Lake OA, Olling M, Barends DM.

In vitro/in vivo correlations of dissolution data of carbamazepine immediate release tablets with pharmacokinetics data obtained in healthy volunteers.

Eur J Pharm Biopharm. 1999; 48: 13-19.

doi:10.1016/S0939-6411(99)00016-8

[17] The United States Pharmacopoeia.

$30^{\text {th }}$ Ed. United States Pharmacopoeial Convention Inc., Rockville, USA; 2007.

[18] Fontana L, Rosati L, Sola A, Dobetti L.

Physicochemical parameters of nitrate esters. A contribution to the choice of a candidate for a preclinical study.

Pharm Acta Helv. 1996; 71: 341-346.

doi:10.1016/S0031-6865(96)00025-8

[19] Jinno J, Oh D, Crison JR, Amidon GL.

Dissolution of ionizable water-insoluble drugs: the combined effect of $\mathrm{pH}$ and surfactant.

J Pharm Sci. 2000; 89: 268-274.

doi:10.1002/(SICI)1520-6017(200002)89:2<268::AID-JPS14>3.0.CO;2-F

[20] Bettinetti G, Mura P, Sorrenti M, Faucci MT, Negri A.

Physical characterization of picotamide monohydrate and anhydrous picotamide.

J Pharm Sci. 1999; 88: 1133-1139.

doi:10.1021/js990150b 
[21] Bertocchi P, Antoniella E, Valvo L, Alimonti S, Memoli A.

Diclofenac sodium multisource prolonged release tablets a comparative study on the dissolution profiles.

J Pharm Biomed Anal. 2005; 37: 679-685.

doi:10.1016/j.jpba.2004.11.041

[22] Center for Drug Evaluation and Research (CDER).

Reviewer Guidance Validation of Chromatographic methods.

Available at

http://www.fda.gov.downloads/Drugs/GuidanceComplianceRegulatorylnformation/Guidances/UCM134 409.pdf (Accessed June 17, 2009).

[23] Tzanavaras PD, Verdoukas A, Balloma T.

Optimization and validation of a dissolution test for famotidine tablets using flow injection analysis.

J Pharm Biomed Anal. 2006; 41: 437-441.

doi:10.1016/j.jpba.2005.12.011

[24] Yuksel N, Kanik AE, Baykara T.

Comparison of in vitro dissolution profiles by ANOVA-based, model-dependent and -independent methods.

Int J Pharm. 2000; 209: 57-67.

doi:10.1016/S0378-5173(00)00554-8

[25] Kassuha D, Steigerwald V, Faudone S, Cuffini S, Sperandeo NR.

Carbamazepine multisource products: in vitro assay of drug release performance and polymorphism.

Pharm Ind. 2009; in press.

[26] Farmacopea Nacional Argentina (FNA).

$7^{\circ}$ Ed., República Argentina, Vol. 1, 2003.

[27] $\mathrm{ICH}$, Harmonized Tripartite Guideline.

Validation of Analytical Procedures: Methodology (Q2B).

International Conference on Harmonization, 1997.

[28] García CV, Paim CS, Steppe M, Schapoval EES.

Development and validation of a dissolution test for rabeprazole sodium in coated tablets.

J Pharm Biomed Anal. 2006; 41: 833-837.

doi:10.1016/j.jpba.2006.01.050 